\title{
Impact of two recent extreme heat episodes on morbidity and mortality in Adelaide, South Australia: a case-series analysis
}

\author{
Monika Nitschke ${ }^{1 *}$, Graeme R Tucker ${ }^{1}$, Alana L Hansen², Susan Williams², Ying Zhang ${ }^{2}$ and Peng Bi ${ }^{2}$
}

\begin{abstract}
Background: Extreme heatwaves occurred in Adelaide, South Australia, in the summers of 2008 and 2009. Both heatwaves were unique in terms of their duration (15 days and 13 days respectively), and the 2009 heatwave was also remarkable in its intensity with a maximum temperature reaching $45.7^{\circ} \mathrm{C}$. It is of interest to compare the health impacts of these two unprecedented heatwaves with those of previous heatwaves in Adelaide.
\end{abstract}

Methods: Using case-series analysis, daily morbidity and mortality rates during heatwaves $\left(\geq 35^{\circ} \mathrm{C}\right.$ for three or more days) occurring in 2008 and 2009 and previous heatwaves occurring between 1993 and 2008 were compared with rates during all non-heatwave days (1 October to 31 March). Incidence rate ratios (IRRs) were established for ambulance call-outs, hospital admissions, emergency department presentations and mortality. Dose response effects of heatwave duration and intensity were examined.

Results: Ambulance call-outs during the extreme 2008 and 2009 events were increased by 10\% and 16\% respectively compared to $4.4 \%$ during previous heatwaves. Overall increases in hospital and emergency settings were marginal, except for emergency department presentations in 2008, but increases in specific health categories were observed. Renal morbidity in the elderly was increased during both heatwaves. During the 2009 heatwave, direct heat-related admissions increased up to 14-fold compared to a three-fold increase seen during the 2008 event and during previous heatwaves. In 2009, marked increases in ischaemic heart disease were seen in the 15-64 year age group. Only the 2009 heatwave was associated with considerable increases in total mortality that particularly affected the 15-64 year age group $(1.37 ; 95 \% \mathrm{Cl}, 1.09,1.71)$, while older age groups were unaffected. Significant dose-response relationships were observed for heatwave duration (ambulance, hospital and emergency setting) and intensity (ambulance and mortality).

Conclusions: While only incremental increases in morbidity and mortality above previous findings occurred in 2008, health impacts of the 2009 heatwave stand out. These findings send a signal that the intense and long 2009 heatwave may have exceeded the capacity of the population to cope. It is important that risk factors contributing to the adverse health outcomes are investigated to further improve preventive strategies.

\section{Background}

Excess mortality and morbidity related to heatwaves have been experienced worldwide over the past 15 years [1-4]. These have been severe enough to initiate preventive action plans in affected cities and at an international level, where efforts are supported by the World Health Organisation [5].

\footnotetext{
* Correspondence: monika.nitschke@health.sa.gov.au

'Department of Health, South Australia, 11 Hindmarsh Square Adelaide

South Australia 5000, Australia

Full list of author information is available at the end of the article
}

Adelaide, the capital city of South Australia (SA) has a population of $1,145,812$ which is $73 \%$ of SA's population. It has a semi arid climate characterised in summer by hot daytime temperatures and cool nights. A recent study in Adelaide explored the potential for intensive and prolonged heat events to be associated with adverse health effects [6]. These results substantiated overseas findings that have shown increased risk of people diagnosed with renal or mental health diseases during heatwaves, as well as a substantial burden placed on ambulance services [7-9]. Increased mortality was not observed except in

\section{Biomed Central}


association with diagnosed mental health disease outcomes.

Towards the end of the warmest decade recorded in Australia, SA experienced a record breaking 15 day heatwave in March 2008 and an exceptionally long and intense heatwave in January to February 2009 [10]. Extremely strained health services were anecdotally reported on both occasions, which led to this comparison of the health impacts of these two unprecedented heatwaves. Associations between health impacts and the duration and intensity of Adelaide's heatwaves were also examined.

\section{Methods}

\section{Health data}

Health data from July 1993 to March 2009 were analysed. While hospital admissions and ambulance call-out data were available for the whole study period, health outcomes-specific mortality data were only available up to December 2007, and emergency department presentation data were only available from July 2003 onwards. The specific health categories used were based on the indicative results from an earlier study and from overseas findings $[6,11,12]$.

For routinely collected hospital admissions, emergency department presentations and mortality (public and private system), the following international classifications of diseases (ICD, revisions 9 and 10) were used: total cardiovascular (ICD-9, 390-4599; ICD-10, I00-99), ischaemic (ICD-9, 410-4149; ICD-10, I20-I25), respiratory (ICD-9, 460-5199; ICD-10, J00-J99), mental (ICD-9, 290-294-9; ICD-10, F00-F999), renal (ICD-9, 580-599; ICD-10 N00N399) and a direct heat-related category comprising dehydration, heat and sunstroke and exposure to excessive heat (ICD-9, 2765, 992, E900; ICD-10, E86, T67, $\mathrm{X} 30)$. The pre-defined categories for ambulance call-outs were obtained from the SA Ambulance Service. Cardiac, respiratory and neurological conditions were included, while ambulance transfers between hospitals were excluded.

\section{Heatwave definition}

An extended period of heat was categorised as a heatwave when the maximum temperature reached $35^{\circ} \mathrm{C}$ or above for three consecutive days or more with $35^{\circ} \mathrm{C}$ marking the $95^{\text {th }}$ percentile for maximum daily temperature for the period 1993-2009. Temperatures were obtained from the SA Bureau of Meteorology measured at a city location representative of the Adelaide metropolitan area [6]. The 2008 heatwave lasted 15 days (3 March-16 March 2008); the 2009 heatwave was defined as a 13 day episode, but included one day where the maximum temperature was just below $35^{\circ} \mathrm{C}$ (26 January7 February 2009).

\section{Statistics}

Average daily rates of adverse health effects in metropoli$\tan$ Adelaide during heatwaves were compared with nonheatwave periods during the warm season (1 October to $31 \mathrm{March}$ ) using case series methodology [13]. Assuming that the exposure temperature is the same for the whole population, the case-series design was modified to apply at the population level using aggregated daily health outcomes in relation to acute risk and control periods. In this form, the case-series approach produces the same result as a case-crossover analysis where all non-heat wave periods in the observation period are used as control time. Case series analysis can only be used for transient exposures with a defined short term risk period. It requires that the probability of exposure is not affected by the occurrence of an outcome event. Cases are used as their own controls in non-risk periods, thus implicitly controlling for all fixed confounders $[13,14]$. The results are expressed as incidence rate ratios (IRR). The analysis was conducted within years; implicitly adjusting for longterm trends. Poisson regression models were fitted in Stata version 10 [15]. Each model was tested for fit, and negative binomial regression models were used to allow for over-dispersion where it occurred

The 2008 and 2009 heatwave days were included in the model as two separate dummy variables providing IRRs for the two hazard periods using the respective within warm season non-heatwave periods as control periods and adjusting for the effects of averaged heatwaves if they occurred during the same warm season. Expected cases were calculated as observed cases divided by the IRR. Excess cases were calculated by subtracting expected from observed cases.

The dose-response relationship for duration was assessed using increasing number of days within a heatwave. As heat events were sparse at the upper duration level, eight or more consecutive heatwave days were combined into one category. Health risks associated with increasing intensity were estimated for every $1^{\circ} \mathrm{C}$ increment in daily maximum temperature above $35^{\circ} \mathrm{C}$.

\section{Results}

According to the definition, a total of 38 heatwave events occurred during the study period. The distribution of maximum temperature and duration during the Adelaide heatwaves is depicted in Figure 1. When excluding the two extreme events, the mean duration of heatwaves was 3.9 days with the longest duration of eight days occurring only twice. The 2008 event was the longest heatwave on record for any Australian capital city with 15 days over $35^{\circ} \mathrm{C}$ and a maximum daily temperature of $40.5^{\circ} \mathrm{C}$. The average minimum temperature was $22.9^{\circ} \mathrm{C}$ and the highest minimum was $30.2^{\circ} \mathrm{C}$. In comparison, the 2009 heatwave was more intense with 


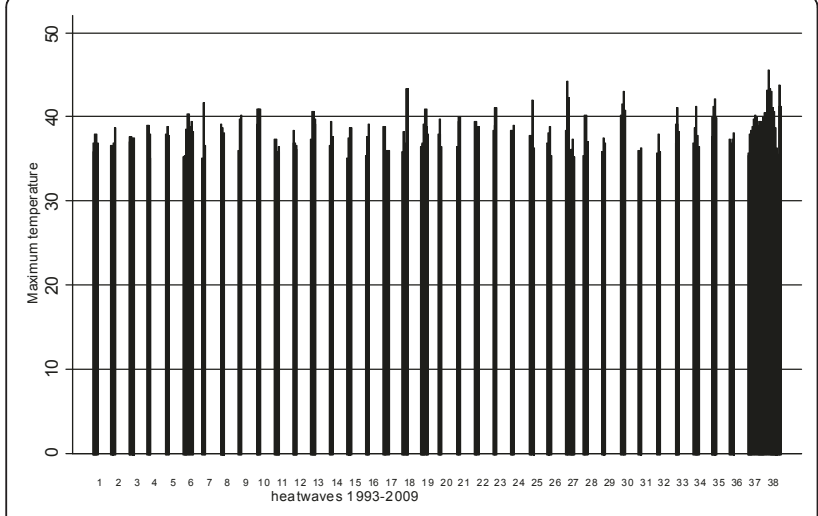

Figure 1 Duration and intensity of heatwaves in Adelaide Distribution of daily maximum temperatures and number of days by heatwaves in Adelaide, 1993-2009.

the maximum temperature soaring to $45.7^{\circ} \mathrm{C}$. The average minimum temperature was $26.1^{\circ} \mathrm{C}$ and the highest minimum was $33.9^{\circ} \mathrm{C}$.

Table 1 provides summary statistics for the average daily rates of ambulance call-outs, hospital admissions, emergency department presentations and mortality during heatwaves and non-heatwave periods over the past 16 years.

\section{Ambulance call-outs}

The increases in daily total ambulance call-outs were 9.7\% during the 2008 heatwave and 16\% during the 2009 event compared to an average 4.4\% increase during previous heatwaves (Table 2). A key difference between the two extreme events and previous averaged heatwaves was the increase in total cardiac-related call-outs. These increased by $9.8 \%$ and $12.7 \%$ respectively, while no increases in cardiac-related call-outs were observed during previous averaged heatwaves. Neurologicalrelated call-outs increased during the two extreme events in the 65-74 year age group, but not in previous averaged heatwaves. During the 2008 heatwave, an increase in respiratory-related call-outs was also seen for the 15-64 year age group. Excess call-outs were estimated to be 360.0 (95\% CI, 108.2-595.7) for the 2008 heatwave, and 517.7 (95\% CI, 288.3-731.9) for the 2009 heatwave.

\section{Hospital admissions}

Small (non-significant) increases in total hospital admissions were observed in all three heatwave categories for the adult age groups (Table 3). Admissions for ischaemic heart disease increased by $33 \%$ (IRR; 1.33 ; 95\%CI, $0.99-1.80$ ) in the 15-64 year age group during the 2009 heatwave only. While increases in mental health related admissions during previous averaged heatwaves were clearly identified across the age groups, this was not as evident during the 2008 and 2009 heatwave. Previous averaged heatwaves have shown significant increases in total renal admissions (IRR1.098; 95\% CI, 1.01-1.20). This trend was repeated during the two extreme events where renal admissions were pronounced in the 5-14 and $75+$ year age groups.

A more than three-fold (IRR 3.12; 95\% CI, 2.51-3.87) increase in total direct heat-related hospital admissions was observed in previous averaged heatwaves, while in 2008, the increase was less than three-fold (IRR 2.62; 95\% CI, 1.32-5.20). However, during the 2009 heatwave, this increase was strengthened to nearly 14-fold (IRR 13.66; 95\% CI, 8.89-20.98), with increases across the adult age range and the highest point estimate in the $75+$ year age group (IRR 19.23; 95\% CI, 12.44-29.7). Overall, an estimated 32.8 (95\% CI, 12.8-42.8) excess heat-related hospital admissions were observed during the 2008 event and 215.0 (95\% CI, 205.9-220.9) excess admissions during the 2009 event.

\section{Emergency Department presentations}

Total emergency department presentations were significantly increased only during the 2008 heatwave (IRR 1.06; 95\% CI, 1.01-1.10) (Table 4). During the 2009 heatwave, increased presentations were restricted to the $75+$ year age group (IRR 1.17; 95\% CI, 1.11-1.22). Previous averaged heatwave data indicate increases in renal emergency department presentations in the 0-4 year age group. During the 2008 heatwave, increases in renal presentations were seen across most age groups. An even larger impact across the age groups manifested during the 2009 heatwave.

The most profound impact was seen on direct heatrelated emergency department presentations, where the IRR for total presentations increased from 2.68 (IRR; 95\% CI, 2.19-3.28) during previous averaged heatwaves to 3.33 (IRR; $95 \% \mathrm{CI}, 2.40-4.62$ ) in 2008 and to 12.01 (IRR; 95\% CI, 9.55-15.12) during the 2009 event. During the 2008 heatwave, there were an estimated 77.6 (95\% CI, 64.7-87.0) excess heat-related emergency department presentations. The presentations during the 2009 heatwave increased across all age groups with an overall excess of 304.4 cases (95\% CI, 297.2-310.0) and the greatest excess of cases (140.5) observed in the $75+$ year age group.

The 2009 heatwave was unique in that ischaemic heart disease-related emergency department presentations rose by $39 \%$ (IRR; $95 \%$ CI, 8-78\%) in the 15-64 year age group. Respiratory-related emergency department presentations were generally unaffected during the 2008 heatwave, while previous averaged heatwave data and 2009 data indicate a reduction in respiratory-related emergency department presentations. As seen with hospital admissions, increases in mental health-related 
Table 1 Descriptive statistics for total and disease-specific health outcomes

\begin{tabular}{|c|c|c|c|c|}
\hline & Minimum & Maximum & Mean & SD \\
\hline Daily ambulance call-outs (5753 observation days) & 84 & 361 & 182.2 & 51.1 \\
\hline non-heat wave periods (cold seasons): 2837 days & 89 & 331 & 183.9 & 50.6 \\
\hline non-heat wave periods (warm seasons): 2748 days & 84 & 336 & 179.4 & 50.8 \\
\hline Heat wave period 08: 15 days: & 248 & 303 & 270.9 & 17.6 \\
\hline Heat wave period 09: 13 days & 243 & 361 & 291.1 & 36.1 \\
\hline Cardiac & 1 & 66 & 27.1 & 8.0 \\
\hline Respiratory & 0 & 48 & 16.0 & 6.7 \\
\hline Neurological & 1 & 48 & 18.9 & 8.8 \\
\hline Daily hospital separation (5753 observation days) & 202 & 1811 & 1086.5 & 465.2 \\
\hline non-heat wave periods (cold seasons): 2837 days & 263 & 1811 & 1103.0 & 461.7 \\
\hline non-heat wave periods (warm seasons): 2748 days & 202 & 1800 & 1066.3 & 469.3 \\
\hline Heat wave period 08: 15 days: & 385 & 1676 & 1248.6 & 508.8 \\
\hline Heat wave period 09: 13 days & 460 & 1742 & 1322.9 & 506.4 \\
\hline Cardio-vascular & 17 & 137 & 73.0 & 24.6 \\
\hline Ischaemic heart disease & 3 & 60 & 24.8 & 8.6 \\
\hline Respiratory & 13 & 138 & 58.7 & 20.8 \\
\hline Mental health & 5 & 214 & 35.6 & 13.5 \\
\hline Renal & 1 & 60 & 21.1 & 9.9 \\
\hline Heat & 0 & 55 & 1.1 & 1.7 \\
\hline Daily Emergency Department (2101 observation days) & 653 & 1263 & 880.3 & 98.4 \\
\hline non-heat wave periods (cold seasons): 1007 days & 658 & 1263 & 879.0 & 102.4 \\
\hline non-heat wave periods (warm seasons): 1020 days & 653 & 1138 & 878.3 & 92.2 \\
\hline Heat wave period 08: 15 days: & 889 & 1129 & 1025.4 & 63.3 \\
\hline Heat wave period 09: 13 days & 905 & 1065 & 994.5 & 54.3 \\
\hline Cardio-vascular & 13 & 63 & 34.8 & 7.7 \\
\hline Ischaemic heart disease & 0 & 22 & 9.6 & 3.3 \\
\hline Respiratory & 23 & 175 & 70.1 & 24.0 \\
\hline Mental health & 0 & 61 & 22.7 & 16.2 \\
\hline Renal & 5 & 46 & 19.0 & 5.8 \\
\hline Heat & 0 & 63 & 2.2 & 3.0 \\
\hline Daily mortality (5753 observation days) & 2 & 44 & 23.7 & 5.4 \\
\hline non-heat wave periods (cold seasons): 2837 days & 7 & 43 & 25.3 & 5.4 \\
\hline non-heat wave periods (warm seasons): 2747 days & 6 & 44 & 22.4 & 5.2 \\
\hline Heat wave period 08: 15 days: & 19 & 31 & 23.2 & 4.2 \\
\hline Heat wave period 09: 13 days & 15 & 44 & 28.6 & 9.4 \\
\hline
\end{tabular}

Daily incidences of ambulance call-outs, hospital admissions (July 1993-March 2009), emergency department presentations (July 2003-March 2009) and mortality (total: 1993-2009; ICD specific: 1993-2006) for metropolitan Adelaide.

emergency department presentations were only observed during previous averaged heatwaves.

\section{Mortality}

A key difference between the 2008 and 2009 heatwaves compared with previous averaged heatwaves was the effect on mortality. During previous averaged heatwaves, there was no evidence of an increase in total or age-specific mortality. Table 5 indicates that during the 2008 heatwave total mortality increased modestly, with the exception of a significant rise in the $0-4$ year age group (IRR 3.23; CI, 1.30-7.99). During the 2009 heatwave, a borderline significant increase in total mortality (IRR 1.10; 95\% CI, 0.991.22) was observed with a significant increase of $37 \%$ (IRR 1.37 ; 95\%CI, 1.09-1.71) in the 15-64 year age group. The older age groups were unaffected. Total estimated excess mortality for the 2009 heatwave was 32.4 (95\% CI,-5.5-67) with 23 (95\%CI, 7.4-35.7) excess deaths in the 15-64 year age groups. Figure 2 shows the progression of mortality during the 2009 heatwave (26 January - 7 February), with 
Table 2 Risk estimates for daily ambulance call-outs

\begin{tabular}{|c|c|c|c|c|c|c|}
\hline \multicolumn{7}{|c|}{ Age groups } \\
\hline Ambulance call-out categories & All ages & $0-4$ & $5-14$ & $15-64$ & $65-74$ & $75+$ \\
\hline \multicolumn{7}{|c|}{ Previous heatwaves } \\
\hline total ambulance & $1.041 .02-1.07$ & $1.040 .96-1.12$ & $0.980 .91-1.06$ & $1.081 .04-1.11$ & $1.030 .99-1.06$ & $1.020 .99-1.05$ \\
\hline cardiac & $0.980 .95-1.02$ & $1.120 .80-1.57$ & $0.640 .26-1.58$ & $1.020 .95-1.08$ & $1.020 .95-1.10$ & $0.940 .89-1.00$ \\
\hline respiratory & $1.000 .95-1.04$ & $1.030 .86-1.24$ & $1.471 .13-1.91$ & $1.020 .93-1.11$ & $0.950 .85-1.06$ & $0.950 .88-1.02$ \\
\hline neurological & $1.010 .97-1.05$ & $1.070 .90-1.28$ & $0.860 .67-1.11$ & $1.030 .98-1.08$ & $1.020 .90-1.17$ & $0.960 .89-1.05$ \\
\hline \multicolumn{7}{|c|}{ Heatwave in 2008} \\
\hline total ambulance & $1.101 .03-1.17$ & $1.090 .87-1.35$ & $1.130 .92-1.37$ & $1.121 .03-1.21$ & $1.131 .03-1.24$ & $1.040 .97-1.13$ \\
\hline cardiac & $1.101 .01-1.20$ & - & - & $1.161 .01-1.34$ & $1.180 .98-1.43$ & $1.020 .89-1.16$ \\
\hline respiratory & $1.060 .94-1.19$ & $1.180 .76-1.86$ & $0.780 .40-1.50$ & $1.321 .08-1.61$ & $0.870 .63-1.18$ & $0.970 .80-1.17$ \\
\hline neurological & $1.08 \quad 0.99-1.19$ & $1.050 .68-1.61$ & $0.610 .28-1.30$ & $1.060 .94-1.20$ & $1.391 .01-1.91$ & $1.110 .90-1.36$ \\
\hline \multicolumn{7}{|c|}{ Heatwave in 2009} \\
\hline total ambulance & $1.161 .08-1.24$ & $1.080 .86-1.36$ & $0.860 .68-1.08$ & $1.141 .04-1.24$ & $1.111 .01-1.23$ & $1.241 .15-1.34$ \\
\hline cardiac & $1.131 .03-1.23$ & - & - & $1.160 .99-1.35$ & $1.060 .86-1.31$ & $1.130 .10-1.29$ \\
\hline respiratory & $0.88 \quad 0.77-1.01$ & $1.050 .67-1.64$ & $0.640 .22-1.90$ & $1.160 .93-1.45$ & $0.780 .55-1.10$ & $0.730 .59-0.92$ \\
\hline neurological & $1.020 .92-1.12$ & $0.940 .59-1.49$ & $0.980 .56-1.72$ & $1.000 .88-1.14$ & $1.350 .97-1.89$ & $0.980 .78-1.24$ \\
\hline
\end{tabular}

Incidence rate ratios and 95\% confidence intervals (Cl) for the effects of previous heatwaves, the 2008 and the 2009 heatwave, by age groups and health-specific effects. Empty cells indicate insufficient data to produce reliable estimates.

Table 3 Risk estimates for daily hospital admissions

\begin{tabular}{|c|c|c|c|c|c|c|}
\hline \multicolumn{7}{|c|}{ Age groups } \\
\hline Hospital admission categories & All ages & $0-4$ & $5-14$ & $15-64$ & $65-74$ & $75+$ \\
\hline \multicolumn{7}{|c|}{ Previous heatwaves } \\
\hline Total & $1.040 .96-1.12$ & $0.990 .97-1.01$ & $0.990 .90-1.09$ & $1.050 .96-1.14$ & $1.050 .96-1.14$ & $1.310 .96-1.11$ \\
\hline Ischaemic & $0.990 .93-1.05$ & & & $1.010 .92-1.12$ & $1.050 .97-1.13$ & $0.910 .85-0.97$ \\
\hline Respiratory & $0.950 .88-1.03$ & $0.880 .79-0.98$ & $1.000 .89-1.13$ & $0.990 .89-1.11$ & $0.940 .88-1.01$ & $0.890 .83-0.95$ \\
\hline Mental health & $1.051 .00-1.10$ & $1.48 \quad 0.99-2.21$ & $1.03 \quad 0.81-1.32$ & $1.040 .99-1.09$ & $1.121 .01-1.24$ & $1.101 .01-1.19$ \\
\hline Renal & $1.101 .01-1.20$ & $1.020 .83-1.26$ & $0.860 .66-1.14$ & $1.131 .03-1.25$ & $1.050 .90-1.23$ & $1.070 .98-1.18$ \\
\hline Direct heat & 3.12 2.51-3.87 & $2.131 .27-3.57$ & $2.000 .95-4.24$ & $2.592 .01-3.33$ & $3.052 .06-4.54$ & $3.652 .92-4.57$ \\
\hline \multicolumn{7}{|c|}{ Heatwave in 2008} \\
\hline Total & $1.060 .84-1.34$ & $0.990 .83-1.18$ & $0.98 \quad 0.73-1.32$ & $1.050 .80-1.36$ & $1.060 .82-1.36$ & $1.110 .90-1.37$ \\
\hline Ischaemic & $1.030 .84-1.25$ & & & $0.970 .71-1.33$ & $1.170 .91-1.49$ & $0.990 .82-1.19$ \\
\hline Respiratory & $0.980 .77-1.24$ & $0.83 \quad 0.59-1.2$ & $1.020 .71-1.47$ & $1.060 .77-1.45$ & $0.910 .72-1.13$ & $0.960 .80-1.15$ \\
\hline Mental health & $0.980 .84-1.14$ & & $1.640 .70-3.87$ & $0.970 .83-1.12$ & $0.870 .62-1.22$ & $1.100 .85-1.41$ \\
\hline Renal & $1.110 .85-1.40$ & $1.120 .60-2.08$ & $2.64 \quad 1.47-4.73$ & $1.00 \quad 0.73-1.38$ & $1.070 .68-1.69$ & $1.231 .03-1.47$ \\
\hline Direct heat & $2.621 .32-5.20$ & & & $2.531 .22-5.25$ & $1.990 .53-7.48$ & 3.05 1.54-6.06 \\
\hline \multicolumn{7}{|c|}{ Heatwave in 2009} \\
\hline Total & $1.080 .84-1.39$ & $1.050 .82-1.26$ & $0.800 .56-1.13$ & $1.08 \quad 0.82-1.42$ & $1.080 .83-1.40$ & $1.140 .91-1.42$ \\
\hline Ischaemic & $1.090 .88-1.33$ & & & $1.330 .99-1.80$ & $0.910 .91-1.49$ & $0.980 .79-1.20$ \\
\hline Respiratory & $0.950 .73-1.22$ & $1.030 .74-1.42$ & $0.650 .41-1.04$ & $0.100 .71-1.41$ & $0.820 .64-1.05$ & $0.980 .84-1.14$ \\
\hline Mental health & $1.030 .88-1.20$ & & $0.840 .34-2.09$ & $1.03 \quad 0.89-1.21$ & $1.030 .74-1.42$ & $1.050 .80-1.36$ \\
\hline Renal & $1.240 .95-1.62$ & $1.160 .67-2.00$ & $0.710 .29-1.74$ & $1.090 .79-1.51$ & $1.380 .89-2.14$ & $1.481 .15-1.88$ \\
\hline Direct heat & $13.668 .89-20.98$ & & & $11.537 .18-18.53$ & $7.063 .05-16.30$ & $19.2312 .44-29.70$ \\
\hline
\end{tabular}

Incidence rate ratios and $95 \%$ confidence intervals (Cl) of the effects of previous heatwaves, the 2008 and the 2009 heatwave by age groups and health-specific effects. Empty cells indicate insufficient data to produce reliable estimates. 
Table 4 Risk estimates for daily emergency department presentations

\begin{tabular}{|c|c|c|c|c|c|c|}
\hline \multicolumn{7}{|c|}{ Age groups } \\
\hline Emergency categories & All ages & $0-4$ & $5-14$ & $15-64$ & $65-74$ & $75+$ \\
\hline \multicolumn{7}{|c|}{ Previous heatwaves } \\
\hline Total & $1.010 .99-1.04$ & $0.960 .91-1.02$ & $0.980 .93-1.03$ & $1.031 .00-1.05$ & $1.030 .99-1.07$ & $1.031 .00-1.06$ \\
\hline Ischaemic & $0.910 .82-1.01$ & & & $0.900 .76-1.06$ & $0.990 .81-1.20$ & $0.880 .75-1.03$ \\
\hline Respiratory & $0.930 .88-1.00$ & $0.960 .89-1.04$ & $1.160 .91-1.46$ & $0.900 .82-0.98$ & $0.880 .75-1.03$ & $0.810 .72-0.91$ \\
\hline Mental & $1.111 .04-1.18$ & $1.980 .78-4.99$ & $0.680 .41-1.14$ & $1.091 .02-1.17$ & $1.591 .22-2.08$ & $1.150 .93-1.43$ \\
\hline Renal & $1.010 .94-1.08$ & $1.301 .01-1.66$ & $0.810 .55-1.19$ & $0.960 .87-1.05$ & $1.140 .92-1.40$ & $1.020 .85-1.22$ \\
\hline Direct heat & $2.682 .19-3.28$ & $1.580 .86-2.91$ & $2.291 .21-4.32$ & $2.992 .24-3.99$ & $2.601 .74-3.89$ & $2.732 .20-3.37$ \\
\hline \multicolumn{7}{|c|}{ Heatwave in 2008} \\
\hline Total & $1.061 .01-1.10$ & $1.020 .92-1.13$ & $1.040 .95-1.14$ & $1.071 .02-1.12$ & $1.091 .02-1.15$ & $1.030 .97-1.08$ \\
\hline Ischaemic & $0.960 .81-1.13$ & & & $0.950 .72-1.23$ & $1.070 .77-1.48$ & $0.900 .69-1.18$ \\
\hline Respiratory & $1.030 .93-1.15$ & $1.050 .89-1.04$ & $1.080 .70-1.66$ & $0.970 .83-1.13$ & $1.210 .96-1.53$ & $1.020 .85-1.22$ \\
\hline Mental & $1.050 .96-1.14$ & $0.560 .08-4.18$ & $0.960 .53-1.73$ & $1.040 .95-1.13$ & $1.240 .85-1.82$ & $1.150 .78-1.51$ \\
\hline Renal & $1.110 .99-1.23$ & $0.800 .48-1.32$ & $1.741 .06-2.85$ & $1.060 .92-1.22$ & $1.300 .94-1.79$ & $1.140 .86-1.53$ \\
\hline Direct heat & $3.332 .40-4.62$ & $0.92 \quad 0.21-4.27$ & $2.110 .62-7.23$ & $4.773 .11-7.30$ & $1.590 .68-3.72$ & 2.95 2.07-4.18 \\
\hline \multicolumn{7}{|c|}{ Heatwave in 2009} \\
\hline Total & $1.020 .98-1.07$ & $0.900 .85-0.95$ & $0.83 \quad 0.74-0.92$ & $1.050 .99-1.10$ & $1.000 .94-1.07$ & $1.171 .11-1.22$ \\
\hline Ischaemic & $1.030 .86-1.23$ & - & - & $1.391 .08-1.78$ & $0.760 .49-1.16$ & $0.840 .61-1.16$ \\
\hline Respiratory & $0.770 .68-0.88$ & $0.720 .62-0.83$ & $0.640 .36-1.14$ & $0.860 .73-1.02$ & $0.800 .61-1.05$ & $0.830 .68-1.00$ \\
\hline Mental & $1.040 .95-1.13$ & $0.620 .83-4.60$ & $0.960 .58-1.59$ & $1.050 .96-1.10$ & $0.660 .40-1.09$ & $1.180 .85-1.64$ \\
\hline Renal & $1.391 .26-1.54$ & $1.511 .02-2.23$ & $1.250 .71-2.21$ & $1.321 .16-1.50$ & $1.210 .87-1.71$ & $1.681 .29-2.10$ \\
\hline Direct heat & $12.019 .55-15.12$ & $3.361 .54-7.30$ & $3.821 .40-10.40$ & $12.408 .80-17.40$ & $9.486 .13-14.65$ & $15.8512 .49-20.12$ \\
\hline
\end{tabular}

Incidence rate ratios and $95 \%$ confidence intervals (Cl) of the effects of previous heatwaves, the 2008 and the 2009 heatwave by age groups and health-specific effects. Empty cells indicate insufficient data to produce reliable estimates.

a steep increase in mortality during four days when consecutive temperatures were in excess of $43^{\circ} \mathrm{C}$ accompanied by unusually hot nights.

\section{Exposure-response}

Using the data from 1993-2009, a dose response relationship was evident between increasing intensity and ambulance call-outs and mortality, while hospital admissions and emergency department presentations were not associated with increasing intensity. For every $1^{\circ} \mathrm{C}$ increment in maximum temperature above $35^{\circ} \mathrm{C}$, ambulance callouts increased by $0.7 \%$ (IRR; $95 \% \mathrm{CI}, 0.4-1.1 \%$ ) and mortality increased by $0.9 \%$ (IRR; $95 \%$ CI, 0.0-1.8\%). A dose response was identified between duration and ambulance callouts (IRR; 1.011 95\% CI, 1.007-1.016), emergency department presentations (IRR 1.009; 95\% CI, 1.006-1.013), and marginally with hospital admissions (IRR 1.019; 95\% CI, 1.00-1.042), but not with mortality (IRR 1.00; 95\%CI, 0.99-1.01).

\section{Discussion}

The main objective of this study was to assess the extent of health effects during the 2008 and 2009 extreme heatwaves in Adelaide and to compare to those for

Table 5 Risk estimates for daily mortality

\begin{tabular}{|c|c|c|c|c|c|c|}
\hline \multicolumn{7}{|c|}{ Age groups } \\
\hline Total mortality & All ages & $0-4$ & $5-14$ & $15-64$ & $65-74$ & $75+$ \\
\hline \multicolumn{7}{|c|}{ Previous heatwaves } \\
\hline & $0.980 .94-1.22$ & $1.150 .81-1.63$ & $1.180 .62-2.28$ & $0.980 .90-1.07$ & $0.990 .91-1.09$ & $0.970 .92-1.01$ \\
\hline \multicolumn{7}{|c|}{ Heatwave in 2008} \\
\hline & $1.050 .94-1.22$ & $3.231 .30-7.99$ & $3.770 .39-36.27$ & $1.010 .57-2.29$ & $1.030 .76-1.38$ & $1.040 .91-1.19$ \\
\hline \multicolumn{7}{|c|}{ Heatwave in 2009} \\
\hline & $1.100 .99-1.22$ & $1.530 .54-5.31$ & $4.330 .45-41.66$ & $1.37 \quad 1.09-1.71$ & $1.150 .86-1.52$ & $1.000 .88-1.15$ \\
\hline
\end{tabular}

Incidence rate ratios and 95\% confidence intervals (Cl) of the effects of previous heatwaves, the 2008 and the 2009 heatwaves by age groups. 


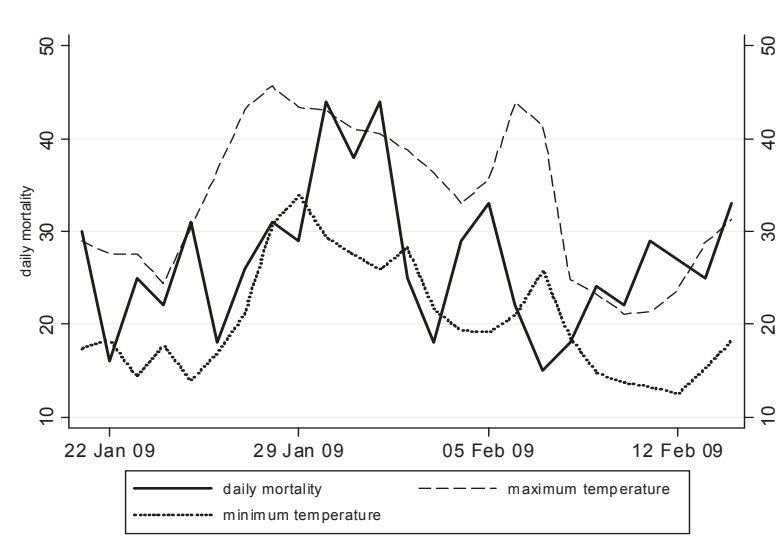

Figure 2 Mortality and temperature during the $\mathbf{2 0 0 9}$ heatwave Daily number of deaths, minimum and maximum temperatures during the 2009 heatwave (26 January-7 February 2009)

averaged heatwaves over the previous years. IRRs for total ambulance call-outs and for total mortality during both extreme events were higher than those for the previous averaged heatwaves, but the 2009 heatwave eclipsed the longer, but less intense 2008 event.

Although total hospital admissions and emergency department presentations were only modestly increased, specific health outcomes such as renal, mental and direct heat-related diseases were affected. Renal diseaserelated increases were of particular concern during the 2009 heatwave. As highlighted in a previous Adelaide study, and substantiated by international studies, heatrelated dehydration appears to promote acute renal failure. Additional factors such as the physiological effects of ageing, personal behaviour, cognitive ability, preexisting chronic disease and related medication use have also shown to contribute to acute renal disease in the elderly and the very young [8-11,16-18].

A 14-fold increase in total direct heat-related hospital admissions was recorded during the 2009 event, compared to a three-fold increase in the previous averaged heatwaves and the 2008 heatwaves. Similar findings have been reported during the concurrent heatwave in Victoria (Australia) and in other cities $[17,19,20]$. However, these findings could possibly be explained by greater accuracy and expertise in reporting of ICD codes for direct heat-related diseases during the 2009 heatwave than in the past because of recurring extreme heat conditions. Although, heat-related disease has the potential for poor short-term and long-term prognosis, it is largely preventable [21,22].

Surprisingly, with the exception of neurological-related ambulance call-outs in the 65-74 year age group, mental health conditions were not significantly affected during the two extreme events, contrary to what was expected based on our previous research and highlighted in the results from previous averaged heatwaves [7]. However, the lack of effects on mental health-related hospital admissions and emergency department presentations may be explained by the relatively small number of mental health-related cases during single heatwave episodes or the effect of preventive actions recently put in place to support susceptible people in Adelaide. These initiatives were introduced during the 2009 heatwave as a result of previous local investigations, and included daily telephone follow up of patients at the severe end of the mental health disease spectrum.

The 2009 event was associated with a substantial increase in hospital admissions and emergency department presentations for ischaemic heart disease, particularly in the 15-64 year age group. Cardiac-related ambulance callouts were also significantly increased during both extreme events. This is consistent with findings from the US, where cardiovascular-related hospital and emergency department admissions were increased during heatwaves $[17,23]$. A recent study in Victoria found that men younger than 65 years have an increased risk of myocardial infarction when temperatures are elevated [24]. This supports our findings of an increased ischaemic heart disease risk in this younger age group. Our previous averaged heatwave data did not suggest effects on cardiac or ischaemic heart disease outcomes and this may be explained by averaging the data over relatively mild heatwaves. This absence of an effect in cardiovascular morbidity agrees with results from a European study where also no effect on heart disease admissions was found [3]. However, The sudden increase in cardiac-related mortality outside of health-care settings during the 2003 heatwave in Paris poignantly demonstrates the immediacy of cardiovascular mortality during extreme heat events suggesting that patients may die prior to presentation at hospital [25]. This is plausible considering the biological impacts of heat on blood viscosity and heart rate, especially in people with pre-existing heart conditions $[26,27]$.

Results from previous averaged heatwaves implied that, on average total mortality during heatwaves is not higher than during non-heatwave periods. However, increased overall mortality was observed during both extreme events, with substantially greater excess deaths during the 2009 event. During the 2009 heatwave in Victoria, mortality increased by $62 \%$, with the greatest increase in the $65+$ years and over age groups which is consistent with findings in other parts of the world $[19,28]$. Whereas in Adelaide there was an increase in total mortality of $10 \%$, and surprisingly, the majority of excess deaths occurred in the 15-64 year age group. When health outcome-specific mortality data becomes available, it will offer further insight into the areas of concern for this age group. Meanwhile, a possible link between the rise of ischaemic heart disease morbidity and the increase in 
mortality in the 15-64 year age group is only speculation. It could be argued that the absence of excess elderly deaths in Adelaide may be due to the generally high standards of care provided to the elderly. Regular telephone calls offering assistance to people at risk during the excessive heat days during the 2009 heatwave may also have contributed to the prevention of heat-related deaths in the older age groups. The higher mortality in Victoria may have been influenced by location-specific parameters. For instance, the prevalence of air-conditioning in homes is $67 \%$ in Melbourne compared to more than $80 \%$ in Adelaide $[29,30]$. This suggests greater preparedness in Adelaide where average summer temperatures are higher than in Melbourne $\left(28.5^{\circ} \mathrm{C}\right.$ versus $25.3^{\circ} \mathrm{C}$ for December, January and February). Acclimatisation to regular hot weather in Adelaide may also play a role. Similar large differences in mortality between cities have been observed overseas and the importance of location-specific parameters and investigations is strongly supported in the heatwave literature $[1,31]$.

In accordance with overseas studies, mortality was instantly elevated on the hottest day of the 2009 heatwave (Figure 1), with only two-day latency until daily mortality peaked leaving a very small window of opportunity for preventive action [32]. This finding ties in with the observed dose response relationship between mortality and heatwave intensity but not with heatwave duration. However, the increasing duration of heatwaves was associated with increases in ambulance, hospital and emergency outcomes which may indicate that vulnerable people eventually visit health services due to accumulating heat effects.

This study design does not allow the recognition of the potential progression of heat-related disease to mortality after heatwaves have ceased, but this will be explored in a future study.

\section{Conclusions}

The results of this study indicate increased health risks during the 2008 and 2009 heatwaves in Adelaide compared to previous averaged heatwaves. Compared to other national and international extreme heat episodes, Adelaide's health outcomes were relatively contained, but a number of important health lessons can be learned for the future. Renal and heat-related morbidity can escalate during extreme heat events and should be targeted for prevention, because of the potentially serious consequences. Unlike the findings from previous heatwave investigations, the 2009 heatwave was associated with excess deaths which are likely to be due to unprecedented intensity over consecutive days. This may indicate that the capacity to cope with heat has been exceeded during this episode. Furthermore, medical social and environmental circumstances underlying the sudden increase in ischaemic heart disease and mortality in the 15-64 year age group during the 2009 heatwave must be explored. Further studies aiming to ascertain specific risk factors that may have contributed to morbidity and mortality during recent extreme heat events in Adelaide are currently underway. Considering the likelihood of increasing incidence and severity of heat events it is crucial to interrogate local data to provide the best evidence for developing and implementing effective heat health prevention in the future.

\section{List of Abbreviations}

SA: South Australia; ICD: international classifications of diseases; IRR: incidence rate ratio.

\section{Author details}

'Department of Health, South Australia, 11 Hindmarsh Square Adelaide, South Australia 5000, Australia. ${ }^{2}$ Discipline of Public Health, University of Adelaide, Adelaide, South Australia 5005, Australia.

\section{Authors' contributions}

MN has designed the study, interpreted the statistical results and wrote the first draft. GT has been involved in data acquisition and ran the statistical analysis. GT was also involved in the interpretation of data and in the revision of the manuscript. $\mathrm{AH}, \mathrm{SW}$ and $\mathrm{YZ}$ have made substantial contribution to the first draft and to the revision. PB has contributed to the study design and edited the article. All authors read and approved the final manuscript.

\section{Competing interests}

The authors declare that they have no competing interests.

Received: 4 February 2011 Accepted: 19 May 2011

Published: 19 May 2011

\section{References}

1. Vandentorren S, Suzan F, Medina S, Pascal M, Maulpoix A, Cohen JC: Mortality in 13 French cities during the August 2003 heat wave. Am J Public Health 2004, 94:1518-1520.

2. Basu R: High ambient temperature and mortality: a review of epidemiologic studies from 2001 to 2008. Environmental Health 2009, 8:40.

3. Michelozzi P, Accetta G, De Sario M, D'Ippoliti D, Marino C, Baccini M, Biggeri A, Anderson HR, Katsouvanni K, Ballester F, Bisanti L, Cadum E, Forsberg B, Forastiere F, Goodman PG, Hojs A, Kirchmayer U, Medina S, Paldy A, Schindler C, Sunyer J, Perucci CA, PHEWE Collaborative Group: High Temperature and Hospitalizations for Cardiovascular and Respiratory Causes in 12 European Cities. Am J Respir Crit Care Med 2009, 179:383-389.

4. Schwartz J, Samet JM, Patz JA: Hospital admissions for heart disease. The effects of temperature and humidity. Epidemiology 2004, 15:755-761.

5. World Health Organisation: Improving public health responses to extreme weather/heat-waves-EuroHEAT - Technical Summary. Copenhagen: WHO Regional Office for Europe; 2009.

6. Nitschke M, Tucker Graeme, Bi Peng: Morbidity and mortality during heatwaves in metropolitan Adelaide. MJA 2007, 187:662-665.

7. Hansen A, Bi P, Nitschke M, Ryan P, Pisaniello D, Tucker G: The effect of heat waves on mental health in a temperate Australian city. Environ Health Perspect 2008, 116:1369-1375.

8. Hansen AL, Bi P, Ryan P, Nitschke M, Pisaniello D, Tucker G: The effect of heat waves on hospital admissions for renal disease in a temperate city of Australia. Int J Epidemiol 2008, 37:1359-1365.

9. Hansen A, Bi P, Nitschke M, Ryan P, Pisaniello D, Tucker G: The Effect of Heatwaves on Ambulance Callouts in Adelaide, South Australia. Epidemiology 2011, 22:S14-S15, [Abstracts: ISEE 22nd Annual Conference, Seoul, Korea, 28 August-1 September 2010: Contributed Abstracts]. 
10. Bureau of Meteorology: Annual Australian Climate Statement 2009. Melbourne 2010 [http://www.bom.gov.au/announcements/media_releases/ climate/change/20100105.shtml].

11. Semenza JC, McCullough JE, Flanders WD, McGeehin MA, Lumpkin JR: Excess Hospital Admissions during the July 1995 Heat wave in Chicago. Am J Prev Med 1999, 16:269-277.

12. Johnson H, Kovats RS, McGregor G, Stedman J, Gibbs M, Walton H, Cook L, Black E: The impact of the 2003 heat wave on mortality and hospital admissions in England. Health Stat Q 2005, 25:6-11.

13. Farrington $\mathrm{CP}$, Whitaker HJ: Semiparametric analysis of case series data. $J$ Royal Stat Soc: Series C (Appl Stat) 2006, 55:553-594.

14. Whitaker $\mathrm{HJ}$, Farrington $\mathrm{CP}$, Spiessens B, Musonda P: Tutorial in Biostatistics: The self-controlled case series method. Stat Med 2005, 0:1-31.

15. Stata Statistical Software Version Release 10 College Station: TX: StataCorp; 2007.

16. Kovats RS, Hajat S, Wilkinson P: Contrasting patterns of mortality and hospital admissions during hot weather and heat waves in Greater London, UK. Occup Environ Med 2004, 61:893-898.

17. Knowlton K, Rotkin-Ellman M, King G, Margoli HG, Smith D, Soloman G, Trent R, English P: The 2006 California heat wave: impacts on hospitalizations and emergency department visits. Environ Health Perspec 2009, 117:61-67.

18. Rikkert MGMO, Melis RJF, Claassen JAHR: Heat waves and dehydration in the elderly. BMJ 2009, 339:b2663.

19. Victorian Government Department of Human Services: January 2009 heatwave in Victoria: an assessment of health impacts. Melbourne, Victoria 2009 [http://www.health.vic.gov.au/chiefhealthofficer/publications/ heatwave.htm].

20. Mastrangelo G, Fedeli U, Visnetin C, Milan G, Fadda E, Spolaore P: Pattern and determinants of hospitalisation during heat waves: an ecologic study. BMC Public Health 2007, 7:200.

21. Bouchama A, Knochel JP: Heat stroke. N Engl J Med 2002, 346:1978-1988.

22. Argaud L, Ferry T, Le QH, Marfisi A, Ciorba D, Achache P, Ducluzeau R, Robert D: Short- and Long-term Outcomes of Heatstroke Following the 2003 Heat Wave in Lyon, France. Arch Intern Med 2007, 167:2177-2183.

23. Semenza JC, Rubin $\mathrm{CH}$, Falter $\mathrm{KH}$, Selanikio JC, Flanders D, Howe HL, Wilhelm JL: Heat-related deaths during the July 1995 heat wave in Chicago. N Engl J Med 1996, 335:84-90.

24. Loughnan ME, Nicholls N, Tapper NJ: When the heat is on: Threshold temperatures for AMI admissions to hospital in Melbourne Australia. Applied Geography 2010, 30:63-69.

25. Empana JP, Sauval P, Ducimetiere P, Tafflet M, Carli P, Jouven X: Increase in out-of-hospital cardiac arrest attended by the medical mobile intensive care units, but not myocardial infarction, during the 2003 heat wave in Paris, France. Crit Care Med 2009, 37:3079-84.

26. Bhaskaran $\mathrm{K}$, Hajat $\mathrm{S}$, Haines $\mathrm{A}$ : Effects of ambient temperature on the incidence of myocardial infarction. Heart 2009, 95:1760-1769.

27. Stafoggia M, Forastiere F, Agostini D, Caranci N, de'Donato F, Demaria M, Michelozzi P, Miglio R, Rognoni M, Russo A, Perucci CA: Factors affecting in-hospital heat-related mortality: a multi-city case-crossover analysis. $J$ Epidemiol Community Health 2008, 62:209-215.

28. Kovats RS, Hajat S: Heat stress and public health: a critical review. Annul Rev Public Health 2008, 29:41-55.

29. Australian Bureau of Statistics: Household Water, Energy Use and Conservation, Victoria. Canberra: ABS; 2009, (ABS Cataloque No. 4602.2)..

30. Australian Bureau of Statistics: Domestic Use of Water and Energy, South Australia. Canberra: ABS; 2004, (ABS Catalogue No. 4618.4).

31. D'Ippoliti D, Michelozzi P, Marino C, de'Donato F, Menne B, Katsouyanni K, Kirchmayer U, Analitis A, Medina-Ramón M, Paldy A, Atkinson R, Kovats S, Bisanti L, Schneider A, Lefranc A, Iñiguez C, Perucci CA: The impact of heat waves on mortality in 9 European cities: results from the EuroHEAT project. Environ Health 2010, 9:37.

32. Michelozzi P, de Donato F, Bisanti L, Ruso A, Cadum E, DeMaria M, D'Ovidio M, Costa G, Perucci CA: The impact of the summer 2003 heat waves on mortality in four Italian cities. Euro Surveill 2005, 10, pii $=556$.

doi:10.1186/1476-069X-10-42

Cite this article as: Nitschke et al: Impact of two recent extreme heat episodes on morbidity and mortality in Adelaide, South Australia: a case-series analysis. Environmental Health 2011 10:42.

\section{Submit your next manuscript to BioMed Central and take full advantage of:}

- Convenient online submission

- Thorough peer review

- No space constraints or color figure charges

- Immediate publication on acceptance

- Inclusion in PubMed, CAS, Scopus and Google Scholar

- Research which is freely available for redistribution

Submit your manuscript at www.biomedcentral.com/submit 